\title{
Neuronal Activity within the Nucleus Basalis and Conditioned Neocortical Electroencephalographic Activation
}

\author{
Paul J. Whalen, Bruce S. Kapp, and Jeffrey P. Pascoe \\ Department of Psychology, The University of Vermont, Burlington, Vermont 05405
}

\begin{abstract}
The relationship between neuronal activity within the nucleus basalis (NB) and conditioned neocortical EEG activation was investigated in New Zealand rabbits during Pavlovian differential conditioning. Twenty-seven of 56 neurons recorded in conditioned animals demonstrated a significantly greater change in activity to a tone $(\mathrm{CS}+)$ that predicted the occurrence of a mildly aversive unconditioned stimulus when compared to a tone (CS - ) that did not. Twenty-four of these 27 neurons demonstrated a significant increase in activity to the $\mathrm{CS}+$ compared to the $\mathrm{CS}-$, while the remaining three neurons demonstrated a significant decrease in activity to the CS+ compared to the CS-. In 24 of these 27 neurons $(89 \%)$ these changes in neuronal activity during CS presentations correlated significantly with a decrease in the power of $\delta$ activity in the EEG. In addition, 13 of these 24 neurons (54\%) demonstrated significant correlations between neuronal activity and the power of $\delta$ activity during CS-free periods. In experimentally naive animals, the activity of 10 of 22 neurons (45\%) recorded within the region of the NB correlated with the power of $\delta$ activity in the EEG during stimulus-free periods. These results complement a growing body of evidence and provide strong support for the hypothesis that the NB contributes to neocortical activation in the conscious animal.
\end{abstract}

[Key words: electroencephalography, nucleus basalis, substantla innominata, rabbit, Pavlovian conditloning, arousal, $\delta$ activity]

The nucleus basalis of Meynert (NB) is a diffuse grouping of neurons within the basal forebrain that projects to widespread areas of the neocortex and that represents the main source of neocortical ACh (Divac, 1975; Mesulam and Van Hoesen, 1976; Johnston et al., 1979; Lehmann et al., 1980; Wenk et al., 1980; Mesulam et al., 1983a,b; Saper, 1984; Russchen et al., 1985). Given the long-term association of $\mathrm{ACh}$ with neocortical activation or arousal (Wikler, 1952; Celesia and Jasper, 1966; Longo, 1966; Szerb, 1967), research has been directed toward the contributions of the NB to neocortical activation, as reflected in low-voltage fast activity or EEG desynchronization. This EEG pattern has long been used as a quantitative, objective measure of different levels of alertness or behavioral arousal in the awake state, with desynchronization reflective of heightened

\footnotetext{
Received June 11, 1993; accepted Aug. 26, 1993.

This study was supported by NSF Grant BNS 9010760 to B.S.K. We thank Dr. William F. Supple for assistance with electrophysiological recording and Jason Fechter for assistance with data analysis.

Correspondence should be addressed to Paul J. Whalen at the above address.

Copyright (C) 1994 Society for Neuroscience $0270-6474 / 94 / 141623-11 \$ 05.00 / 0$
}

behavioral arousal, and synchronization, or the enhanced incidence of high-amplitude slow activity, reflective of decreased arousal (Jasper and Carmichael, 1935; Rheinberger and Jasper, 1937).

Recent research has demonstrated that stimulation of the NB produces EEG desynchronization (Berladetti et al., 1977; Casamenti et al., 1986; Metherate et al., 1992) and increases in the extracellular concentration of $\mathrm{ACh}$ in the neocortex (Casamenti et al., 1986). Furthermore, lesions of the NB that deplete the neocortex of ACh produce an increase in high-amplitude slow activity (e.g., $\delta$ activity) in the EEG (Stewart et al., 1984; Buzsaki et al., 1988; P. Riekkinen Jr. et al., 1990) similar to that observed after administration of cholinergic antagonists (Longo, 1966; Buzsaki et al., 1988; Metherate et al., 1992). A contribution for the $\mathrm{NB}$ in neocortical activation receives additional support from the findings that (1) stimulation of the NB facilitates the responsiveness of sensory neocortical neurons to sensory stimuli (Metherate and Ashe, 1991), (2) lesions of the NB reduce the responsiveness of neurons in the visual cortex to visual stimuli (Sato et al., 1987), and (3) ACh, when applied to neocortical sensory neurons, produces a striking enhancement of their response to sensory stimuli (Sillito and Kemp, 1983; Metherate et al., 1987, 1988).

These combined observations are consistent with the notion that cholinergic neurons of the NB function to activate the neocortex, providing a cortical state that reflects an enhanced readiness of neurons to respond to afferent input and perhaps providing a cellular substrate for an enhanced state of behavioral alertness or arousal. Such a function would dictate that neurons within the NB region should respond to stimuli that elicit behavioral and neocortical arousal, as reflected in EEG desynchronization. Indeed, neurons within the NB region demonstrate altered rates of activity in response to stimuli predictive of reward (Rigdon and Pirch, 1986; Richardson and Delong, 1990; Wilson and Rolls, 1990), stimuli that presumably elicit increased levels of behavioral arousal. Furthermore, Detari and Vanderwolf (1987) have demonstrated in the urethane-anesthetized rat that neurons within the NB increase their activity during periods of EEG desynchronization in response to tailpinch. In addition, Buzsaki et al. (1988) observed that NB neurons in the rat fired at a higher rate during walking, when the EEG was characterized by desynchronization, than during immobility, when the EEG showed a higher incidence of $\delta$ activity. However, a systematic, quantitative analysis of the extent to which the activity of these neurons correlates with the magnitude of EEG desynchronization in the conscious animal in the presence of emotionally arousing stimuli that elicit EEG desynchronization has yet to be undertaken. The present study, there- 
fore, was designed to determine if (1) neurons within the NB respond differentially to conditioned auditory stimuli that signal either the presence or absence of a mildly aversive event and that therefore elicit differential levels of neocortical arousal as reflected in EEG desynchronization in the conscious rabbit, and (2) the activity of these neurons in response to these stimuli significantly correlates with the magnitude of the EEG desynchronization responses elicited by these stimuli.

To elicit differential levels of EEG desynchronization, New Zealand rabbits were trained in a Pavlovian differential conditioning paradigm in which a tone of one frequency, the CS+, was always followed by a brief electrical current applied to the pinna (i.e., the unconditional stimulus or US) and a tone of another frequency, the CS-, was never followed by the US. Recent data from our laboratory have demonstrated that over the course of conditioning significantly greater EEG desynchronization responses are elicited by the $\mathrm{CS}+$ than by the $\mathrm{CS}-$, reflecting a differentially conditioned change in the animal's level of arousal to the presentation of these stimuli (Kapp et al., 1991). Single neurons within the region of the NB were isolated and recorded (1) in response to $\mathrm{CS}+$ and $\mathrm{CS}-$ presentations following the establishment of differentially conditioned EEG desynchronization responses, and (2) during stimulus-free periods in order to determine correlations between their activity and the magnitude of EEG desynchronization as determined by fast Fourier transformation.

\section{Materials and Methods}

\section{Animals}

Twenty experimentally naive New Zealand rabbits (Orvctolagus cuniculus) weighing from 2.3 to $2.6 \mathrm{~kg}$ at the start of the experiment were used. They were maintained on a 12:12 hr light/dark cycle and given food and water ad libitum. Principles for the care and use of laboratory animals in research, as outlined by the National Institutes of Health (1985), were strictly followed.

\section{Surgical procedure}

Following application of topical lidocaine $(4 \%)$ to the region of the marginal ear vein, all animals were anesthetized by an injection of PromAce (acepromazine; $4 \mathrm{mg} / \mathrm{kg}$ ) followed by sodium pentobarbital $(30-60 \mathrm{mg} / \mathrm{kg}, \mathrm{i} . \mathrm{v}$.). The animal was mounted into a Kopf stereotaxic instrument fitted with a rabbit headholder, a midline incision was made over the skull, and holes were drilled to provide access to the brain for the recording of single neurons and for placement of EEG electrodes. EEG recording electrodes constructed from stainless steel jeweler's screws were placed anterior to bregma so as to rest upon dura above the frontal cortex $(7.0 \mathrm{~mm}$ anterior and $3.0 \mathrm{~mm}$ lateral to bregma; bregma adjusted $1.5 \mathrm{~mm}$ above lambda). An indifferent electrode was inserted into the skull posterior to bregma $(6.0 \mathrm{~mm}$ posterior and $3.0 \mathrm{~mm}$ lateral to bregma) and a ground electrode was placed into the skull overlying the cerebellum. Nylon bolts for head immobilization were then attached to the skull with cyanoacrylate cement. An indifferent electrode, used for the recording of single neurons and composed of a stainless steel wire insulated except at the cross-sectional tip, was placed into the neocortex. For the purpose of single neuron recording, a stainless steel electrode well, designed to accommodate a miniature hydraulic microdrive (Trent Wells Co.), was positioned over a hole in the skull $(1.5 \mathrm{~mm}$ anterior and $4.0 \mathrm{~mm}$ lateral to bregna) to provide for stereotaxic access to the NB. The well was secured in place with cyanoacrylate cement and sealed with a nylon plug. The entire exposed skull was then covered with dental cement. Animals were closely monitored following surgery until they regained postural control and were monitored daily thereafter for a $7 \mathrm{~d}$ postsurgical recovery period following which behavioral experiments began.

\section{Apparatus}

During the experiment animals were placed in a Plexiglas restrainer with an adjustable headstock and padded backplate. The restrainer was placed within a shielded, ventilated, and sound-attenuating recording chamber (Industrial Acoustics Co.) that was equipped with a $24 \mathrm{~cm}$ speaker situated $48 \mathrm{~cm}$ in front of the animal, and a modified stereotaxic frame used to immobilize the animal's head. Responses of single neurons were amplified by a high-impedance, differential preamplifier (DAM50, World Precision Instruments) couplcd with a main amplificr (7P511, Grass Instruments) and a custom-made active filter, for a total system gain of approximately $25 \mathrm{k}$ and a bandwidth of $0.3-10 \mathrm{kHz}$. Responses from single neurons were isolated, fed to an audio monitor and a window discriminator (Frederick Haer and $\mathrm{Co}$.), and displayed on a storage oscilloscope. Two independent output channels of a Grass S88 stimulator were used to administer the US to the pinna during behavioral conditioning and to produce anodal DC marker lesions ( $100 \mathrm{~mA}$ anodal $\mathrm{DC}$ for $5 \mathrm{sec}$ ) at the end of selected, daily recording sessions. The EEG was amplified and recorded using Grass model 7P511 amplifiers and a Grass model 78 polygraph. Neuronal responses, EEG, verbal commentary, and event markers were recorded on a multichannel FM tape recorder (A.R. Vetter Co.). The neuronal responses were fed into a laboratory minicomputer (ABLE 40, New England Digital Co.) for onlinc data analysis. This computer also controlled the presentation of stimuli during the conditioning procedure. The EEG was analyzed off line by digitizing the taped signal using a sampling frequency of $128 \mathrm{~Hz}$ and subjecting it to a fast Fourier transformation using a Med Associates data acquisition and fast Fourier analysis software package.

\section{Behavioral training}

Following surgical recovery the animal was placed into the restrainer within the recording chamber for five, daily, $1 \mathrm{hr}$ sessions, and the head was immobilized by attachment of the nylon bolts to the modified stereotaxic frame. On the day following the last habituation session, a Pavlovian differential conditioning procedure was administered. Eighteen pseudorandom presentations each of two tones of differing frequency ( 530 and $1280 \mathrm{~Hz}, 90 \mathrm{~dB}, 5.0 \mathrm{sec}$ ) were administered so that no more than two consecutive presentations of either tone were permitted (orienting trials). A variable $120 \mathrm{sec}$ intertrial interval was used. These trials were necessary in order to habituate the EEG orienting response, a desynchronization commonly observed in animals in response to the presentation of a novel stimulus. Twenty-four pseudorandom presentations of each tone were then administered, with the offset of one tone (the $\mathrm{CS}+$ ) being coincident with the onset of the US $(500 \mathrm{msec}, 1.0$ $\mathrm{mA}, 60 \mathrm{~Hz}$ stimulus train applied to the pinna). The second tone (the CS - ) was never followed by the US (conditioning trials). The US was administered via two stainless steel wire loops that pierced the pinna and were spaced approximately $2.0 \mathrm{~cm}$ apart. They were inserted under local lidocaine anesthesia $24 \mathrm{hr}$ prior to behavioral conditioning. The designated tone frequencies for the $\mathrm{CS}+$ and the CS- were counterbalanced among animals. To optimize conditioned discrimination between the $\mathrm{CS}+$ and $\mathrm{CS}-$, a second differential conditioning session, again composed of 24 presentations each of the CS + and the CS-, was administered $24 \mathrm{hr}$ later. The $2 \mathrm{~d}$ of behavioral conditioning were followed by three, daily, electrophysiological recording sessions.

\section{Electrophysiological recording procedure}

Recordings from single neurons were made via platinized, tungsten microelectrodes (5-10 M $\Omega$ tip impedance; Frederick Haer and $\mathrm{Co}$.). The microelectrode was advanced toward the NB using a hydraulic microdrive (Trent Wells Co.). Successive electrode penetrations took place on subsequent days and were spaced $0.2-1.0 \mathrm{~mm}$ apart. The criteria for successful isolation of a single neuron were as follows: (1) waveform constancy during the observation period, (2) sufficient waveform amplitude to enable reliable and unambiguous discrimination, (3) a waveform duration indicating somatodendritic origin (spike duration greater than $1.0 \mathrm{msec}$ ), and (4) a 3:1 signal-to-noise ratio.

Following isolation, an interspike interval histogram was generated over a $30 \mathrm{sec}$ period in order to characterize rates and patterns of spontaneous activity. Six presentations each of the CS+ and CS - were then presented in a pseudorandom sequence using a variable $120 \mathrm{sec}$ intertrial interval. Each trial consisted of a $5 \mathrm{sec}$ pre-CS baseline period and the $5 \mathrm{sec}$ CS period. Following the completion of these 12 trials, a second set of 12 identical trials was administered provided the neuron could be sufficiently isolated for the necessary duration. Additional blocks of conditioning trials (six CS + and six CS - trials) in which the $\mathrm{CS}+$ was followed by the US were administered as needed to maintain 
the conditioned discrimination. These trials were administered following the completion of the recording from an individual neuron.

\section{Analysis of EEG data}

Fast Fourier analysis yielded a numerical value representing the absolute power for each of the following frequency bands within the EEG for the $5 \mathrm{sec}$ immediately preceding the CSs and during the $5 \mathrm{sec}$ CS periods: $1-4 \mathrm{~Hz}, \delta ; 4-8 \mathrm{~Hz}, \theta ; 8-12 \mathrm{~Hz}, \alpha ; 12-20 \mathrm{~Hz}, \beta$. The suppression of slowwave, $\delta$ activity $(1-4 \mathrm{~Hz})$ was used in defining the effects of CS+ and $\mathrm{CS}-$ presentations on the EEG. The rationale for the use of $\delta$ activity in assessing the effects of CS presentations was based on several observations. First, $\delta$ wave activity has been used in recent experiments to assess the effects of manipulations of the NB on the EEG (Buzsaki et al., 1988; P. Riekkinen Jr. et al., 1990). It is therefore used in the present study to maintain consistency with these recent studies. Second, it is suppressed during the EEG desynchronization observed in response to the presentation of conditioned stimuli in the awake rabbit (Kapp et al., 1991). Third, it is also suppressed during the release of acetylcholine in the neocortex (Szerb, 1967). Fourth, it is increased by antimuscarinic agents (Buzsaki et al., 1988; Metherate et al., 1992), and fifth, it is increased by excitotoxic lesions of the cholinergic neurons of the NB (Buzsaki et al., 1988; P. Riekkinen Jr. et al., 1990).

The effects of CS presentations on the EEG were expressed as a percentage change in $\delta$ power from the $5 \mathrm{sec}$ pre-CS period. These percentage change scores were then used to assess EEG changes to CS trials statistically by using separate two-factor (CS type $\times$ trial block) within-subject ANOVAs for the orienting trials and differential conditioning trials of behavioral training. The absolute power of $\delta$ was used during electrophysiological recording sessions in order to determine the existence of correlations between the EEG and neuronal activity during CS presentations and during CS-free periods.

\section{Analysis of electrophysiological data}

Peristimulus time histograms. Peristimulus time histograms were generated for each block, consisting of six CS+ and six CS - trials. The number of neuronal action potentials (spikes) occurring in consecutive $10 \mathrm{msec}, 100 \mathrm{msec}$, or $1 \mathrm{sec}$ bins was counted by the computer, resulting in a peristimulus histogram of the frequency of neuronal activity before and during each CS type.

$C S$ response analysis. To access statistically the reliability of a neuron's response to either the CS+ or CS-, the mean and SD for the pre$\mathrm{CS}$ baseline distribution of neuronal activity (expressed as spikes/1.0 sec bin) were calculated. $Z$ score equivalents were then derived for the spike counts during each $1.0 \mathrm{sec}$ of either the CS + or CS-presentations. $Z$ scores that exceeded 1.96 ( $95 \%$ confidence interval) were considered to represent a statistically significant change in neuronal activity during a CS.

$C S$ onset latency analyses. To evaluate the onset latency of a neuron's response to CS presentations, $Z$ scores for 10 consecutive $10 \mathrm{msec}$ bins after CS onset were calculated. The bin that contained the first significant $Z$ score was considered to represent the latency of that neuron's response to the CS. The mean latency for a group of similarly responding neurons was then determined through cumulative summation of onset latency data.

$C S+/ C S-$ differential response analyses. To statistically characterize the differential responsiveness of groups of similarly responding neurons to the six CS+ and six CS- presentations, mean neuronal responses during the 5 sec CS presentations were compared using two-tailed $t$ tests for related measures.

Correlational analyses. The degree to which changes in the activity of neurons in response to the CSs correlated with changes in the EEG to these CSs was determined by calculating the correlation between neuronal activity (expressed as spikes per $5 \mathrm{sec} C \mathrm{C}$ period) and EEG (expressed as the power of $\delta$ activity per $5 \mathrm{sec} C S$ period) during a 12trial block of six CS+ and six CS- trials.

Two additional analyses were used to determine if a relationship existed between neuronal activity and EEG activity during CS-free periods. First, during the pre-CS periods correlations between the activity of neurons (expressed as spikes per $5.0 \mathrm{sec}$ pre-CS period) and the EEG (expressed as the power of $\delta$ per $5.0 \mathrm{sec}$ pre-CS period) were determined. Second, correlations between neuronal activity and EEG activity during stimulus-free periods were determined in experimentally naive animals. In this analysis, following the isolation of a single neuron, $60 \mathrm{sec}$ continuous samples of neuronal and concomitant EEG activity were re-
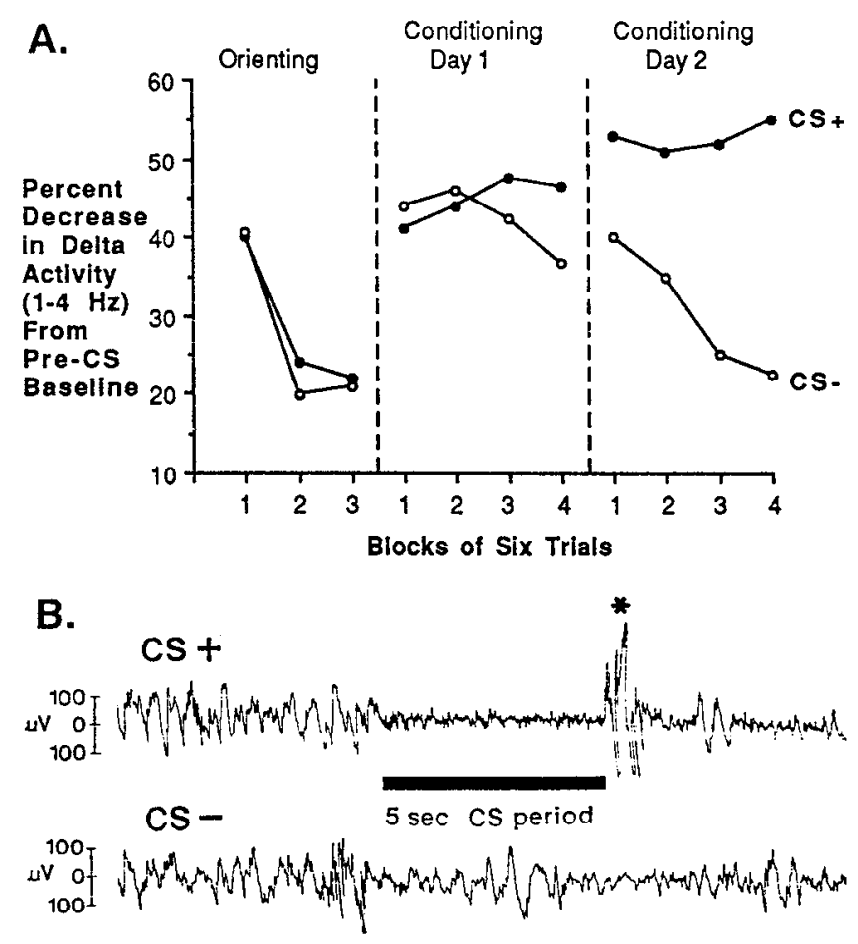

Figure 1. The acquisition of the conditioned EEG desynchronization response. $A$, The $x$-axis represents blocks of trials consisting of six presentations each of the CS + and $C S-$ presented over $2 \mathrm{~d}$ of conditioning. The $y$-axis represents the mean percentage decrease in the power of $\delta$ activity during CS presentations compared to the pre-CS baseline. $B$, Examples of the EEG during CS + and $\mathrm{CS}-$ trials recorded during block three on the second day of conditioning in an individual animal are presented. Asterisk denotes US-induced movement artifact.

corded. This $60 \mathrm{sec}$ period was broken down into 12 successive $5 \mathrm{sec}$ bins and correlations were derived from the neuronal activity (total number of spikes) and EEG data ( $\delta$ power) across these 12 bins.

\section{Histology}

Animals were killed with an overdose of sodium pentobarbital (150 $\mathrm{mg} / \mathrm{kg}$, i.v.) and perfused with physiological saline followed by $10 \%$ formal-saline solution. Forty micrometer frozen sections were taken through the rostral-caudal extent of the NB. Alternate sections were stained with thionin or, in selected animals, for acetylcholinesterase (AChE) according to the method described by Mesulam (1982). The latter stain was used to determine the location of recording sites with reference to the cholinergic neurons of the NB. The location of these sites was determined microscopically by comparing microdrive coordinates with the relative electrode tract positions and marker lesions.

\section{Results}

Differential Pavlovian conditioning of EEG desynchronization

The EEG data were analyzed for 10 rabbits that received 2 full days of conditioning and yielded neurons that were responsive to CS presentations.

Orienting trials. As shown in Figure $1 \mathrm{~A}$, initial, unreinforced, tone presentations produced EEG desynchronization orienting responses depicted here as the percentage decrease in $\delta$ activity during the CSs when compared to the 5 sec pre-CS baseline period. Note that the large percentage decrease in $\delta$ activity during the first six-trial block of tone presentations habituates across successive trials. A two-factor (CS type $\times$ trial block) within-subjects ANOVA confirmed this significant trials effect $[F(2,54)=11.71, p<0.001]$. Neither the CS type main effect nor the CS type $\times$ trial block interaction was statistically sig- 
Figure 2. Line drawings depicting the locations of recorded neurons in conditioned and experimentally naive animals within the region of the NB: $A$ is most anterior; $C$ is most posterior. $\mathrm{Sol}$ id circles, neurons that demonstrated a significant increase in activity to $\mathrm{CS}+$ versus $\mathrm{CS}-$ presentations in conditioned animals; open circles, neurons that demonstrated a significant decrease in activity to $\mathrm{CS}+$ versus CSpresentations in conditioned animals; solid squares, neurons that demonstrated significant negative correlations with the power of $\delta$ activity in the EEG in experimentally naive animals; open squares, neurons that demonstrated significant positive correlations with the power of $\delta$ activity in the EEG in experimentally naive animals. $a c$, anterior commissure; $C$, caudate; $e c$, external capsule; $G P$, globus pallidus; $i c$, internal capsule; $N L O T$, nucleus of the lateral olfactory tract; ot, optic tract; $P$, putamen; $S I$, substantia innominata.

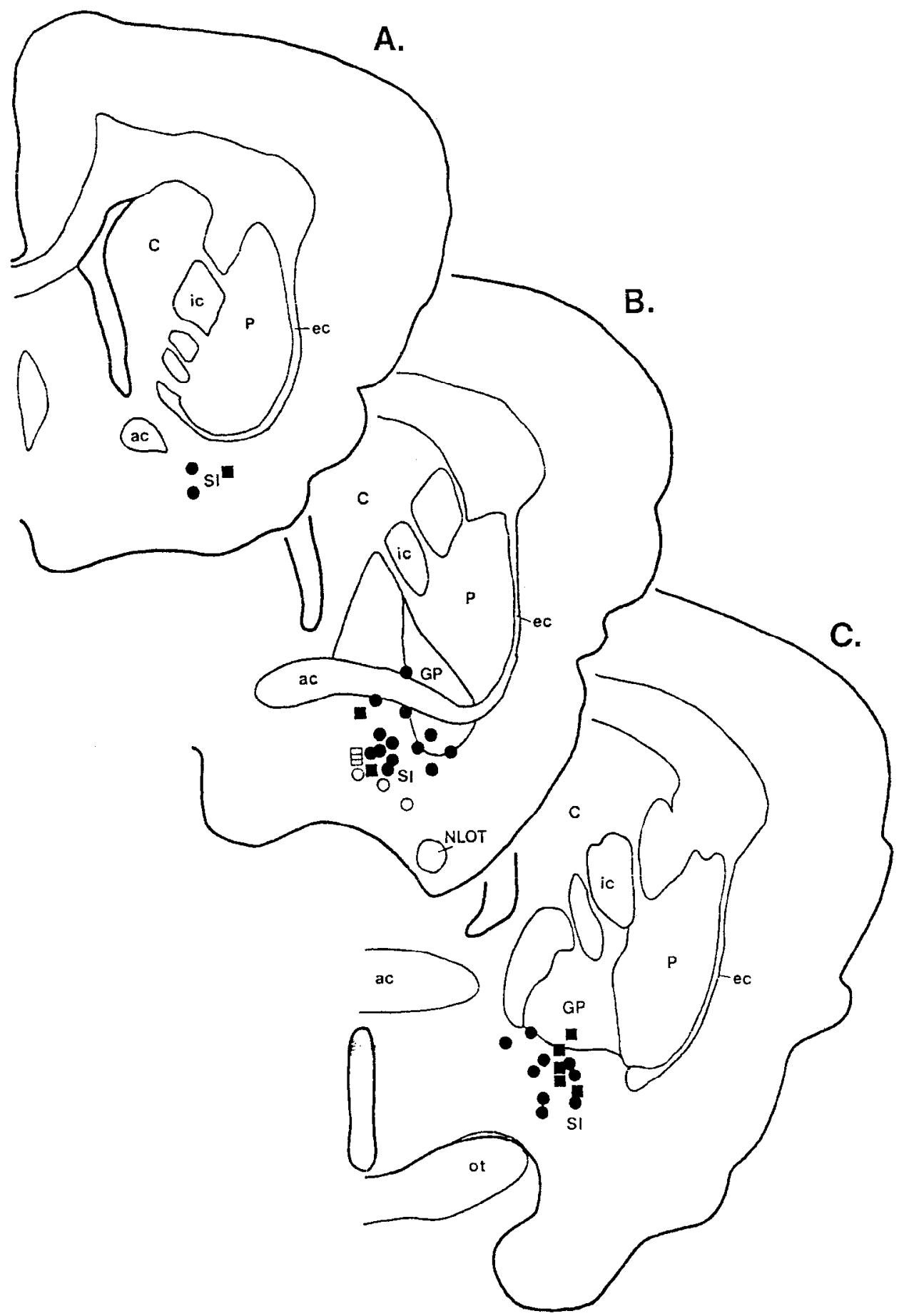

nificant, demonstrating that the magnitude and course of habituation of these responses were independent of the $\mathrm{CS}+$ and CS- tone frequencies.

Differential conditioning trials. Also shown in Figure $1 A$ is the emergence of differential EEG desynchronization responses to the two CSs over the $2 \mathrm{~d}$ of Pavlovian conditioning. Note the development of a greater desynchronization response, as reflected in a greater percentage decrease in $\hat{\delta}$ activity, during presentations of the CS+ when compared to the CS-. A twofactor (CS type $\times$ trial block) within-subjects ANOVA revealed a significant CS type effect $[F(1,144)=41.21, p<0.001]$, and a reliable CS type $\times$ trial block interaction $[F(7,144)=4.95$, $p<0.001]$. The trial block factor was not significant. The significant CS type and CS type $\times$ trial block interaction demonstrate that EEG desynchronization responses during CS + presentations were statistically distinguishable from those during CS - presentations. The lack of a trials effect may reflect the rapidity with which the enhanced EEG response to the $\mathrm{CS}+$ emerges over trials.

Figure $1 B$ presents examples of EEG activity during a $\mathrm{CS}+$ and a $\mathrm{CS}$ - trial for a representative animal. Note the more pronounced EEG desynchronization response during the $\mathrm{CS}+$ than during the $\mathrm{CS}-$, a response that was maintained during subsequent neuronal recording sessions. 

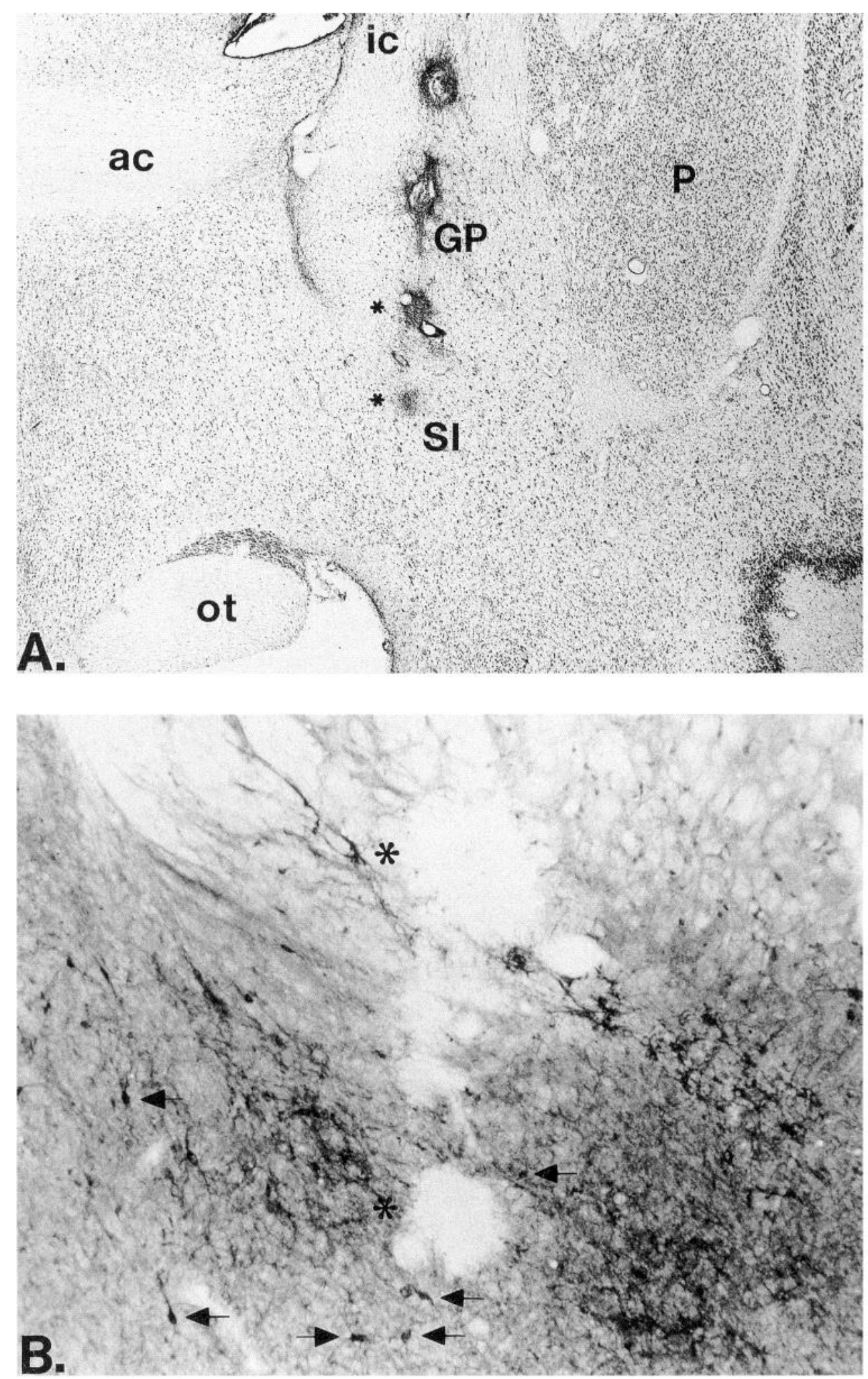

Figure 3. An example of a recording electrode track in an individual animal Top, A thionin-stained section that depicts the track through the internal capsule, globus pallidus, and substantia innominata. Note the four marker lesions along the extent of this track, each spaced $1 \mathrm{~mm}$ apart. Sensory-responsive neurons were recorded from the two most ventral lesion sites (asterisks) within the ventral globus pallidus (more dorsal placement) and the substantia innominata (more ventral placement). Bottom, A higher-power photomicrograph of a section adjacent to that at the top showing the two most ventral lesion sites stained for $\mathrm{AChE}$ to detect the presence of cholinergic neurons. $A r$ rows depict neurons stained for $\mathrm{AChE}$. $a c$, anterior commissure; $G P$, globus pallidus; $i c$, internal capsule; ot, optic tract; $P$, putamen; $S I$, substantia innominata.

\section{Location of $C S$-responsive neurons}

Of 56 neurons from which recordings were made in this study, 27 were responsive to the CSs and were included in the statistical analyses. The remaining 29 neurons were not responsive to CS presentations as determined by the lack of responsiveness to at least two presentations each of the $\mathrm{CS}+$ and $\mathrm{CS}-$. Figure 2 depicts the location of these 27 neurons on line drawings of the region of the NB. As depicted in the figure, the neurons from which recordings were taken were within the region of the substantia innominata and the ventral globus pallidus, where large numbers of the cholinergic neurons of the NB are located (Divac, 

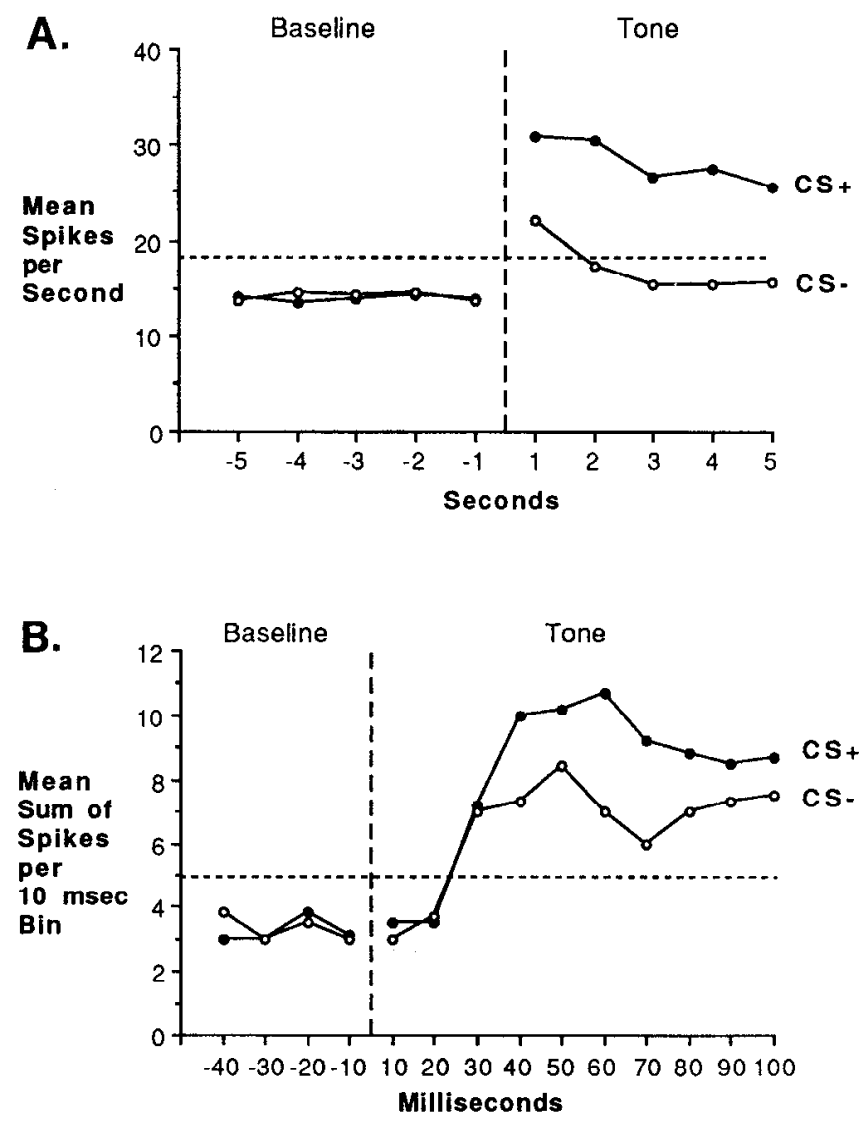

Figure 4. Mean response of 24 of 27 neurons recorded within the region of the $\mathrm{NB}$ that demonstrated a significant increase in activity to the presentation of the CS + when compared to the CS-.A. The $x$-axis represents the $5 \mathrm{sec}$ pre-CS baseline period and the $5 \mathrm{sec}$ CS period. The $y$-axis represents the mean number of action potentials (spikes) per $1 \mathrm{sec}$ bin for these 24 neurons. The horizontal hroken line indicates a significant increase in activity from the pre-CS baseline period as determined by standard score analysis $(Z>1.96, p<0.05) . B$, Response latency of these 24 neurons. The $x$-axis presents a $40 \mathrm{msec}$ pre-CS baseline period and the first $100 \mathrm{msec}$ of the CS period. The $y$-axis represents the mean sum of spikes per $10 \mathrm{msec}$ bin for these 24 neurons.

1975; Mesulam and Van Hoesen, 1976; Johnston et al., 1979; Lehmann et al., 1980; Saper, 1984). Figure 3 presents an example of a recording electrode track in an individual animal.

\section{Response characteristics of neurons within the region of the NB following differential Pavlovian conditioning}

Standard score analyses revealed a significant increase in response rate during the $\mathrm{CS}+$ for 24 of the $27 \mathrm{CS}$-responsive neurons $(Z$ values $>1.96, p<0.05$ ). The baseline firing rates for these 24 neurons were quite heterogeneous, ranging from 0.4 to $27.6 \mathrm{~Hz}[\bar{X}-14.02 \pm 8.68$ (SD) Hz]. The increase in activity during the $\mathrm{CS}+$ for these 24 neurons was significantly greater than that during the $\mathrm{CS}-[t(23)=11.79, p<0.0001]$. The mean data for these 24 neurons are presented in Figure 4. Note the significant increase in activity across the entire $5 \mathrm{sec}$ period during the $\mathrm{CS}+$, but only during the first second of the $5 \mathrm{sec}$ CS - period. Standard score analysis revealed a significant increase in activity during the third $10 \mathrm{msec}$ bin (i.e., 21-30 msec) following the onset of either the CS+ or CS- ( $Z$ values $>1.96, p<0.05$ ).

Of the 24 neurons that demonstrated significantly greater responses to the CS + than to the CS-, $21(88 \%)$ demonstrated
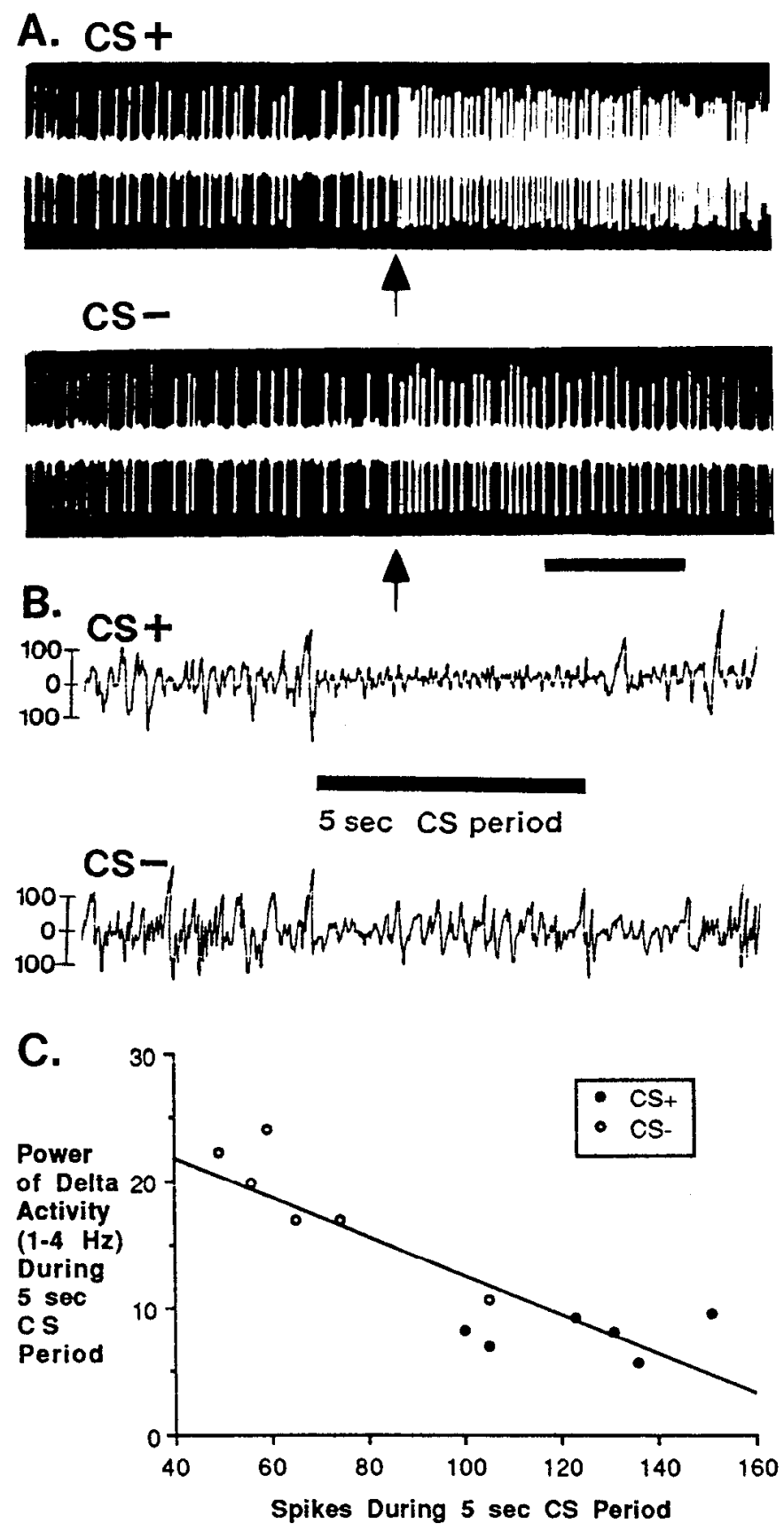

Figure 5. An example of an individual neuron recorded within the region of the NB that demonstrated a significantly greater increase in activity to the presentation of the $\mathrm{CS}+$ when compared to the $\mathrm{CS}-. A$, Oscilloscope traces of temporally adjacent CS + and CS- trials demonstrating the $2.5 \mathrm{sec}$ prior to CS onset and the first $2.5 \mathrm{sec}$ of the CS period. The arrow depicts CS onset. Time calibration, 1 sec. $B$, EEG responses for the same CS+ and CS- trials presented in $A$. Note the more pronounced EEG desynchronization response to the CS+ when compared to the CS.$- C$, The correlational analysis depicting the negative relationship between the activity of this neuron and the power of $\delta$ activity in the EEG during six presentations each of the CS + and CS$(r=-0.81, p<0.05)$.

significant, negative correlations between the rate of neuronal firing to CS presentations and the power of $\delta$ activity during CS presentations; that is, the lower the power of $\delta$ activity during the CSs, the greater the response rate of the neuron during the CSs $(r$ values $=-0.51$ to $-0.89, p$ values $<0.05)$. Figure 5 
CONDITIONED ANIMAL (A)

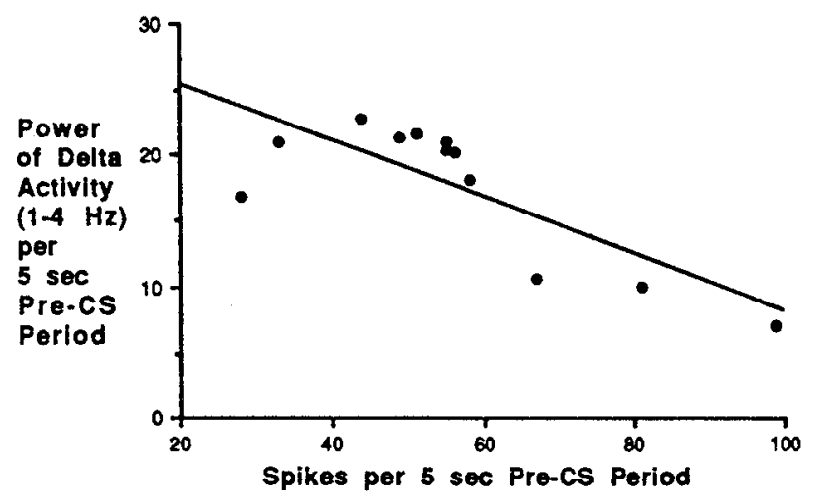

EXPERIMENTALLY-NAIVE ANIMAL (B)

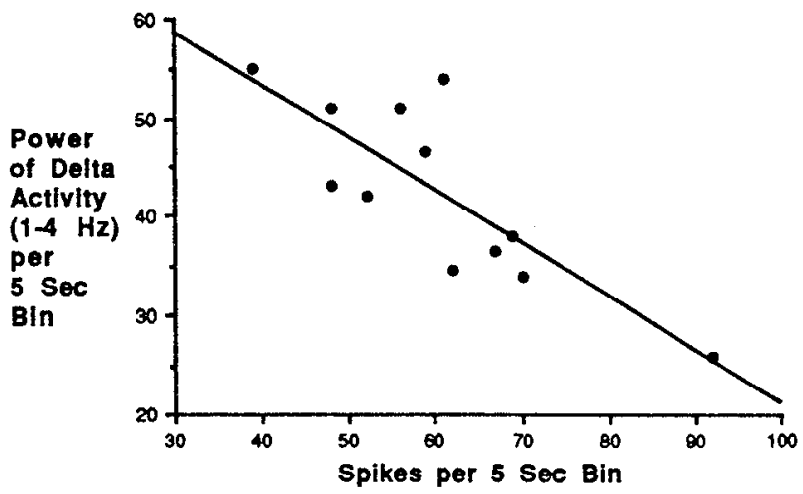

A.

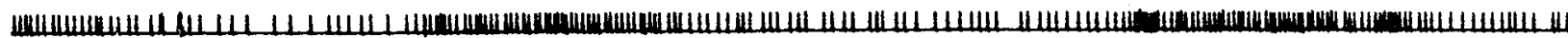

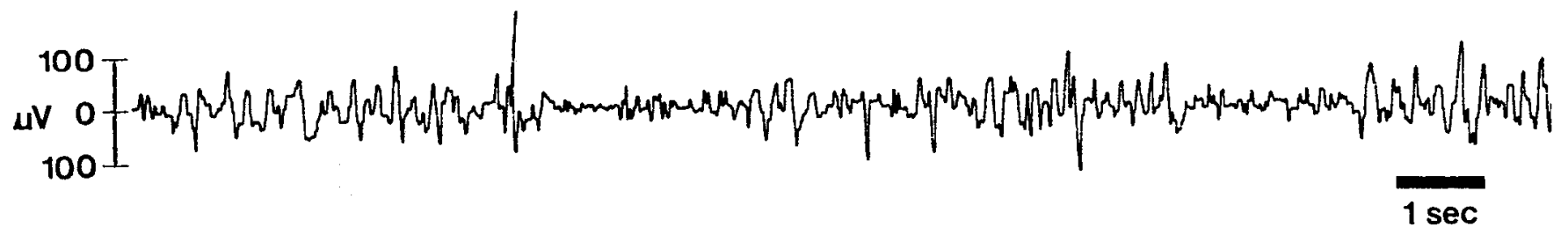

B.

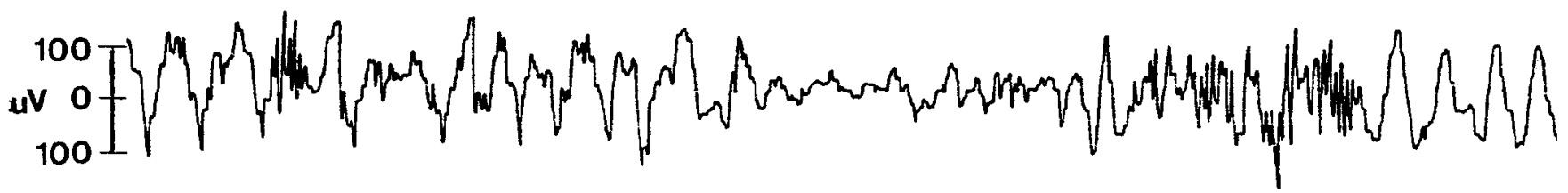

Figure 6. Examples of the negative correlation between the activity of a neuron recorded within the region of the NB and EEG activity in a conditioned animal $(r=-0.79, p<0.05)$ during CS-free periods (i.e., during the intertrial interval) and in an experimentally naive animal $(r=$ $-0.80, p<0.05$ ). $A$, Example of raw EEG (lower trace) and tick marks representing action potentials from the recorded neuron (upper trace) in the conditioned animal whose correlational data is presented above. $B$, Traces same as in $A$ for the experimentally naive animal whose correlational data are presented above. Note that increases in neuronal activity are associaled with a decreased presence of high-amplitude slow-wave activity in the EEG.

presents the data from a representative neuron from this group of 21 .

Of the 27 neurons that were responsive to CS presentations, three demonstrated a significantly greater decrease in activity to the CS + than to the CS - as determined by standard score analyses $(Z$ values $>1.96, p$ values $<0.05)$. The baseline firing rates for these three neurons ranged from 18.84 to $22.7 \mathrm{~Hz}[\bar{X}$ $=20.85 \pm 1.94(\mathrm{SD}) \mathrm{Hz}]$. All three neurons that decreased their activity during CS presentations demonstrated significant, positive correlations with the power of $\delta$ activity; that is, the lower the power of $\delta$ activity during the CSs, the lower the response rate of the neuron during the CSs $(r$ values $=0.51,0.58$, and $0.81 ; p$ values $<0.05$ )

Thesc significant correlations during CS presentations indicate that both the EEG and neuronal activity reliably differentiated between the $\mathrm{CS}+$ and $\mathrm{CS}-$. In order to determine whether these significant correlations might also reflect a linear relationship between conditioned EEG and neuronal response magnitudes, a second correlation was calculated based only upon data collected during CS - presentations. CS - presentations, as opposed to $\mathrm{CS}+$ presentations, were chosen for this analysis due to the inherent variability in the power of $\delta$ activity during the former and the relative lack thereof during the latter. That is, the low amount of variability in the power of $\delta$ activity to CS + presentations in the well-trained animal does not permit the appropriate conditions to assess linear relationships. Seven of the neurons that demonstrated significant correlations between the power of $\delta$ activity and neuronal activity also demonstrated significant correlations between these two measures during $\mathrm{CS}-$ presentations $(r$ values $=-0.81$ to -0.95 and 0.95 ; $p$ values $<0.05$ ).

\section{Relationship between EEG and neuronal activity during stimulus-free periods}

To determine the extent to which a relationship existed between the EEG and neuronal activity in CS-responsive neurons during 

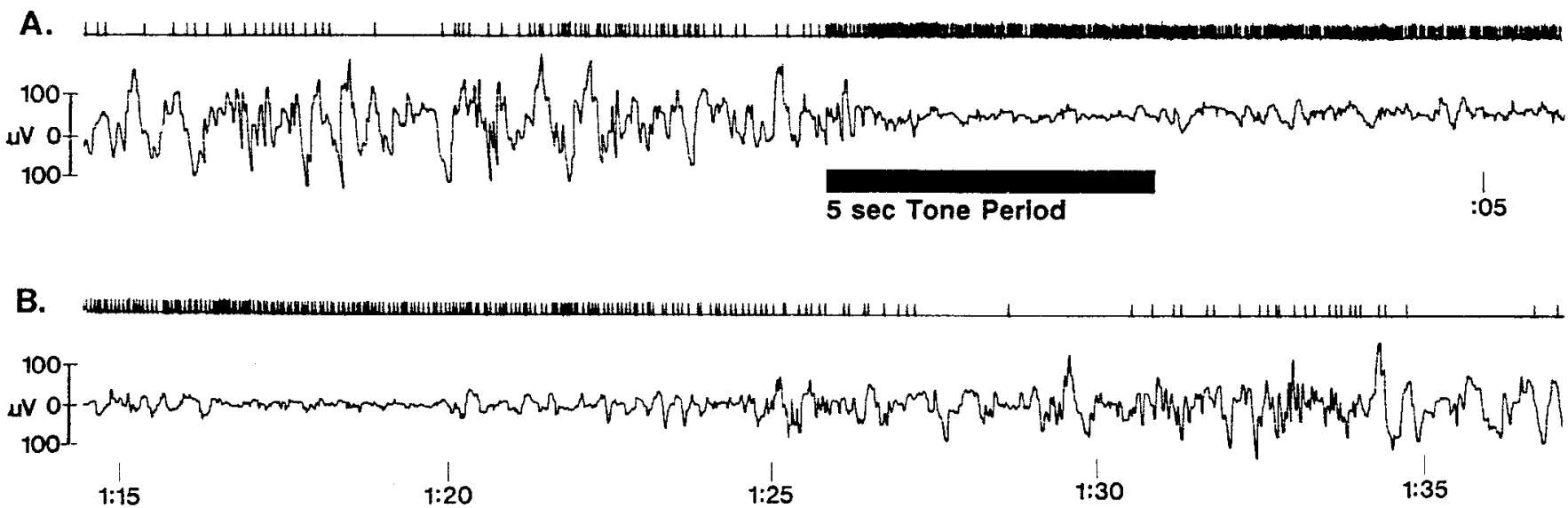

Figure 7. Example of concomitant EEG and neuronal responses of a neuron within the region of the NB to the first presentation of a 5 sec, 530 $\mathrm{Hz}$ tone in an experimentally naive animal. $A$, Note that the increase in activity of this neuron outlasts the tone presentation. $B$, The return to pretone activity levels (approximately $1 \mathrm{~min}$ and $25 \mathrm{sec}$ following tone offset) is coincident with the reappearance of high-amplitude slow-wave activity in the EEG trace. Tick marks in upper trace are as in Figure 6.

CS-free periods, correlations between the neuronal activity and the power of $\delta$ activity during the $5 \mathrm{sec}$ pre-CS baseline period were determined. Of the 24 neurons that demonstrated significant correlations during CS presentations, significant correlations during CS-free periods were obtained in $13(54 \%)$. In 11 of these neurons the correlations were negative ( $r$ values $=-0.50$ to $-0.79, p$ values $<0.05$ ); that is, the greater the neuronal activity, the less the amount of $\delta$ activity in the EEG. In the remaining two neurons the correlations were positive; that is, the less the neuronal activity, the less the power of $\delta$ activity ( $r$ values $=0.68$ and $0.77, p$ values $<0.05$ )

In an additional determination of the relationship between neuronal and EEG activity, recordings were made from 22 neurons in the region of the NB in six cxpcrimentally naive rabbits. Of these 22 neurons, significant correlations were obtained in 10. In eight of these neurons the correlations between EEG and neuronal activity were negative ( $r$ values $=-0.64$ to $-0.89, p$ values $<0.05)$, while in two neurons the correlations were positive $(r$ values $=0.52$ and $0.59, p$ values $<0.05)$. The locations of these neurons are depicted in Figure 2. Figure 6 presents an

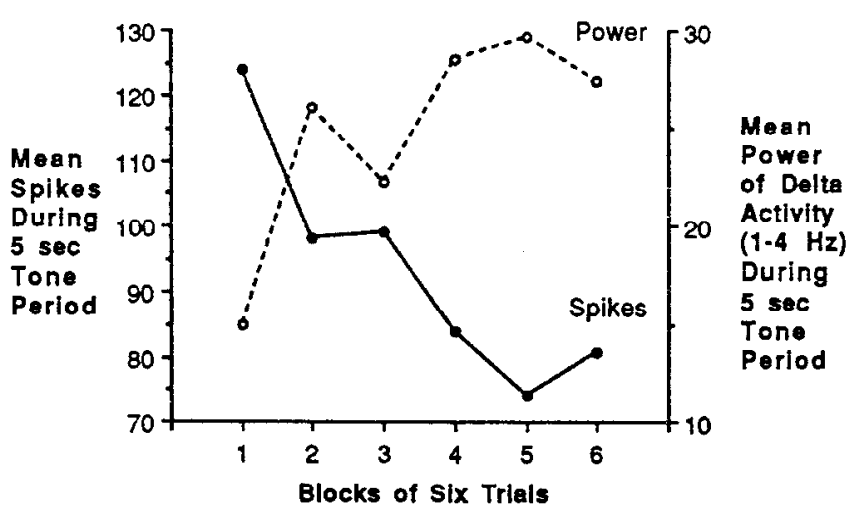

Figure 8 . Example of one of the three neurons that demonstrated a significant correlation between the activity of a neuron in the region of the NB and the EEG during CS orienting trials $(r=-0.96, p=0.05)$. The $x$-axis represents blocks of three presentations each of the two CS frequencies. The left $y$-axis represents the mean number of spikes (solid circles, solid line), while the right $y$-axis represents the mean power of $\delta$ activity (open circles, dashed line) during the CSs. example of the relationship between neuronal and EEG activity during stimulus-free periods in a conditioned rabbit and in an experimentally naive rabbit.

In three experimentally naive animals the responses of three neurons that demonstrated significant, negative correlations between neuronal activity and the power of $\delta$ activity were recorded to tone presentations during orienting trials. All three neurons responded with a significant increase in activity during the initial presentations of the $5 \sec$ CSs $(Z$ values $>1.96, p<$ $0.05)$. Similar to the EEG response, this increased activity outlasted the duration of the CS, returning to pre-CS firing levels as $\delta$ activity began to reappear following CS offset (Fig. 7). Figure 8 presents the neuronal response data for one of these neurons, plotted in conjunction with the animal's EEG responses, during $18 \mathrm{CS}+$ and $18 \mathrm{CS}-$ orienting trials. Note that the decrease in neuronal activity during the CSs over repeated trials is associated with an increase in the power of $\delta$ activity. Significant negative correlations were found between the neuronal responses and the power of $\delta$ activity over the course of these orienting trials for all three neurons $(r$ values $=-0.54,-0.78$, and $-0.96 ; p$ values $<0.05$ )

\section{Discussion}

\section{Conditioning of the EEG}

Consistent with an existing older literature (Jasper and Shagass, 1941; Motokawa, 1949; Morrell, 1961), the results of the present study demonstrated the acquisition of a differentially conditioned EEG desynchronization response during a Pavlovian differential conditioning procedure. This conditioned response was observed to be acquired at a ratc similar to that previously demonstrated in the rabbit using a nondifferential Pavlovian conditioning procedure and a pseudoconditioning control group to demonstrate its associative nature (Yehle et al., 1967). Recent research in our laboratory has demonstrated that a centrally acting, but not peripherally acting, cholinergic antagonist markedly attenuated the expression of this response (Kapp et al., 1991), a result consistent with earlier findings that demonstrated a contribution for $\mathrm{ACh}$ in EEG desynchronization (Celesia and Jasper, 1966; Szerb, 1967). Furthermore, that this response is rapidly acquired and reflects neocortical arousal or an enhanced readiness to respond to afferent input is consistent with its char- 
acterization as a nonspecific (Weinberger, 1982) or preparatory (Konorski, 1967; see also Wagner and Brandon, 1989) conditioned response. Such responses can be considered to reflect a conditioned change in the central state of the organism, most commonly referred to as heightened arousal (Weinberger, 1982).

\section{Conditioning of neuronal responses within the region of the $N B$}

The results of the present study demonstrated that neurons within the region of the NB responded differently to a tone (CS+) that predicted the occurrence of a mildly aversive US than to a second tone $(\mathrm{CS}-)$ that never predicted the occurrence of the US. These results are consistent with previous results that demonstrated altered rates of activity of neurons in the region of the NB during the presentation of stimuli predictive of the imminent occurrence of important events. For example, neurons within this region show altered activity (i.e., increases and decreases) in response to visual, auditory, or somatosensory stimuli predictive of reward, including food, water, and rewarding brain stimulation (Rigdon and Pirch, 1986; Richardson and DeLong, 1990; Wilson and Rolls, 1990). Furthermore, in monkeys large changes in the activity of these neurons have been observed in response to somatosensory stimuli predictive of water reward with substantially smaller changes observed in response to a qualitatively different somatosensory stimulus prcdictive of the absence of water reward (Richardson et al., 1988). Similar to the results of the present study, these latter results demonstrate that NB neurons display differentially conditioned activity. The results of the present study extend these findings by demonstrating that neurons in the region of the NB respond differentially to auditory stimuli predictive of the presence or absence of an aversive event. More importantly, the activity of these neurons correlated with an objective, quantitative measure of neocortical activation or arousal. This latter point will be developed in more detail later in the Discussion.

While the associative nature of the response of neurons within the region of the NB is reflected in their discriminative responses to CS + and CS - presentations, the extent to which the plasticity required for this associative responding is inherent to the neurons of the NB will require much additional research. Nevertheless, consistent with this notion are the observations that single NB neurons are responsive to stimuli of varying modalities, and neural theories of the plasticity underlying Pavlovian conditioning dictate that convergence of CS and US sensory information must occur at the site(s) of plasticity (Pascoe et al., 1991). Alternatively, the associative nature of neuronal responding demonstrated by NB neurons may be relayed to the NB from sites afferent to this structure, including the amygdala, locus coeruleus, nucleus raphe magnus, pedunculopontine and lateral dorsal tegmental nuclei of the pons, and the insular cortex (Russchen et al., 1985; Grove, 1988; Jones and Cuello, 1989; Zaborszky et al., 1991). Prominent among these are the amygdaloid central nucleus and the locus coeruleus. Activation of either nuclei (Kreindler and Steriade, 1964; Berridge and Foote, 1991; Kapp et al., 1994) elicits EEG desynchronization. In addition, neurons within both nuclei have been reported to increase their activity immediately prior to EEG desynchronization (Langhorst et al., 1987; Berridge and Foote, 1991). Finally, short-latency associative neuronal responses have been recorded in both structures during Pavlovian conditioning (Pascoe and Kapp, 1985; Rasmussen et al., 1986), with latencies not incon- sistent with the notion that either of these two regions, or both, might serve to relay associative responding to the NB.

\section{Cortical projections and the cholinergic nature of recorded neurons}

The extent to which neurons from which recordings were made in this study were cortical projection neurons was not determined. Nevertheless, similarities between the characteristics of recorded neurons in this study and those from previous studies in which antidromic activation techniques were utilized to identify NB cortical projection neurons are highly suggestive that a significant number of neurons from which recordings were made in the present study were cholinergic, cortical projection neurons of the NB. Previous studies have shown that NB cortical projection neurons demonstrate locations, baseline firing rates, and EEG correlations similar to neurons recorded in the present study. With respect to location, antidromically activated neurons were located primarily in the ventral globus pallidus and the substantia innominata, but were never located in the more dorsal regions of the globus pallidus (Aston-Jones et al., 1984; Lamour et al., 1986; Detari and Vanderwolf, 1987; Reiner et al., 1987; Richardson and DeLong, 1987). Without exception, recordings from sensory-responsive neurons in the present study were made at the ventralmost region of the globus pallidus or within the substantia innominata. With respect to baseline firing rates, the mcan bascline firing ratc and the heterogencity of rates reported in the present study are similar to cortical projection neurons recorded from in previous studies (Aston-Jones et al., 1984; Lamour et al., 1986; Detari and Vanderwolf, 1987; Reiner et al., 1987; Richardson and DeLong, 1987). With respect to correlation with the EEG, the activity of all cortical projection neurons recorded by Detari and Vanderwolf (1987) correlated with EEG desynchronization, while the activity of neurons that could not be antidromically activated never correlated with EEG desynchronization. In the present study, the activity of a significant percentage of neurons during CS - presentations and during stimulus-free periods demonstrated significant correlations with the power of $\delta$ activity. These similarities between the neurons recorded in the present study and those reported in previous studies strongly suggest that a significant number of the recorded neurons that correlated with the EEG during stimulus-free periods and CS - presentations in the present study were cortical projection neurons, the large majority of which are known to be cholinergic within this region (Mesulam et al., 1983a; Rye et al., 1984; Koliatsos et al., 1990).

\section{Correlations between EEG and neuronal activity}

The most important finding to emerge from the present research was the observation that significant correlations were found between the neuronal activity and the power of $\delta$ activity for a substantial number of neurons within the region of the NB. Indeed, $89 \%$ of neurons that responded differentially during tone presentations demonstrated significant correlations between their activity and the amount of $\delta$ activity during these presentations, thereby indicating that both the EEG and neuronal activity reliably differentiated between the $\mathrm{CS}+$ and $\mathrm{CS}-$. The finding of significant correlations between the power of $\delta$ activity and neuronal activity during CS - presentations for $29 \%$ of these neurons suggested a linear relationship between these two variables. Additionally, the activity of $54 \%$ of these neurons correlated significantly with the amount of $\delta$ activity in the EEG during CS-free periods. This latter finding in conditioned animals was 
consistent with the observation in experimentally naive animals that the activity of neurons within the region of the NB was correlated significantly with the amount of $\delta$ activity in the EEG. Two important points emerged from the findings of significant correlations during stimulus-free periods. First, while the magnitude of the correlation coefficients suggests that the neuronal activity in the region of the NB can account for a substantial amount of the variability in the power of $\delta$ activity, a substantial amount of variability remains to be explained. This is particularly noteworthy in light of recent findings suggesting the contribution of other structures, including the locus coeruleus and the median and dorsal raphe nuclei, to EEG desynchronization (Berridge and Foote, 1991; Peck and Vanderwolf, 1991). Second, the fact that such correlations were observed during stimulus-free periods lends additional support to the notion that the observed correlations reflect a linear relationship between the power of $\delta$ and neuronal activity.

It is important to emphasize that significant correlations between the power of $\delta$ and neuronal activity were not observed in a substantial number of neurons within the region of the NB. The reason(s) for the absence of such correlations is unknown, but may pertain to the observation that the cholinergic neurons that comprise the NB are distributed within several regions that contain noncholinergic cell groups (e.g., the extended amygdala; see Alheid and Heimer, 1988) that do not project to cortex as well as cholinergic neurons that project to regions other than cortex (Levey et al., 1987; Steriade et al., 1987; Jourdain et al., 1989; Zaborszky et al., 1991; Emre et al., 1992). The absence of correlations may reflect the fact that recordings were taken from neurons located within these regions that do not project to cortex. Alternatively, the absence of correlations as demonstrated by these neurons may simply be due to the insensitivity and vagaries of the EEG as a response with which to derive correlations with the activity of neurons.

Nevertheless, the correlations observed in this study are con sistent with earlier research that suggested the contribution of the NB to neocortical activation. For example, in the rat, electrical stimulation of the NB produces EEG desynchronization (Belardetti et al., 1977; Casamenti et al., 1986; Metherate et al, 1992), whereas damage to the NB produces an increase in the power of $\delta$ activity (Stewart et al., 1984; Buzsaki et al., 1988; P. Rickkincn Jr. et al., 1990). In addition, in an autopsy study P. J. Riekkinen et al. (1990) have reported that Alzheimer's patients with the highest amounts of EEG $\delta$ power exhibited the lowest cell density scores in the NB. These accumulated results, along with those of the present study demonstrating that the activity of a substantial number of neurons within the region of the NB correlated with the power of $\delta$ activity in the EEG, complement a growing body of evidence and provide strong support for the hypothesis that the NB contributes to neocortical activation in the conscious animal.

\section{References}

Alheid GF, Heimer L (1988) New perspectives in basal forebrain organization of special relevance to neuropsychiatric disorders: the striatopallidal, amygdaloid, and corticopetal components of substantia innominata. Neuroscience 27:1-39.

Aston-Jones G, Shaver R, Dinan T (1984) Cortically projecting nucleus basalis neurons in rat are physiologically hetcrogencous. Neurosci Lett 46:19-24.

Belardetti F, Borgia R, Mancia M (1977) Prosencephalic mechanisms of ECoG desynchronization in cerveau isole cats. Electroencephalogr Clin Neurophysiol 42:213-225.
Berridge CW, Foote SL (1991) Effects of locus coeruleus activation on electroencephalographic activity in neocortex and hippocampus. J Neurosci 11:3135-3145.

Buzsaki G, Bickford RG, Ponomareff G, Thal LJ, Mandel R, Gage FH (1988) Nucleus basalis and thalamic control of neocortical activity in the freely moving rat. J Neurosci 8:4007-4026.

Casamenti F, Defenu G, Abbamondi AL, Pepeu G (1986) Changes in cortical acetylcholine output induced by modulation of the nucleus basalis. Brain Res Bull 16:689-695.

Celesia GG, Jasper HH (1966) Acetylcholine released from cerebral cortex in relation to state of activation. Neurology 16:1053-1064.

Detari L, Vanderwolf CH (1987) Activity of identified cortically projecting and other basal forebrain neurones during large slow waves and cortical activation in anesthetized rats. Brain Res 437:1-8.

Divac I (1975) Magnocellular nuclei of the basal forebrain project to the neocortex, brain stem, and olfactory bulb. Brain Res 93:385-398.

Emre M, Guela C, Mesulam M-M (1992) Cholinergic innervation of the human amygdaloid complex. Soc Neurosci Abstr 18:976.

Grove EA (1988) Efferent connections of the substantia innominata in the rat. J Comp Neurol 277:347-364

Jasper HH, Carmichael L (1935) Electrical potentials from the intact human brain. Science 81:51-53.

Jasper $\mathrm{HH}$, Shagass C (1941) Conditioning of the occipital alpha rhythm in man [sicb. J Exp Psychol 28:373-388.

Johnston MV, McKinney M, Coyle JT (1979) Evidence for a cholinergic projection to neocortex from neurons in basal forebrain. Proc Natl Acad Sci USA 76:5392-5396.

Jones BE, Cuello C (1989) Afferents to the basal forebrain cholinergic cell area from ponto-mesencephalic catecholamine, serotonin and acetylcholine neurons. Neuroscience 31:37-61.

Jourdain A, Semba K, Fibiger HC (1989) Basal forebrain and mesopontine tegmental projections to the reticular thalamic nucleus: a collateralization and immunohistochemical study in the rat. Brain Res 505:55-65.

Kapp BS, Whalen PJ, Thurm SL (1991) Cholinergic contributions to cortical electroencephalographic (EEG) conditioned responses (CRs) in the rabbit. Soc Neurosci Abstr 17:322.

Kapp BS, Supple WF Jr, Whalen PJ (1994) The effects of electrical stimulation of the amygdaloid central nucleus on neocortical arousal in the rabbit. Behav Neurosci, in press.

Koliatsos VE, Martin LJ, Price DL (1990) Efferent organization of the mammalian basal forebrain. In: Brain cholinergic systems (Steriade M, Biesold D, ed), pp 120-152. Oxford: Oxford UP.

Konorski J (1967) Integrative activity of the brain. Chicago: University of Chicago.

Kreindler A, Steriade M (1964) EEG patterns of arousal and sleep induced by stimulating various amygdaloid levels in the cat. Arch Ital Biol 102:576-586.

Lamour Y, Dutar P, Rascol O, Jobert A (1986) Basal forebrain neurons projecting to the rat frontoparietal cortex: electrophysiological and pharmacological properties. Brain Res 362:122-131.

Langhorst P, Lambertz M, Schulz G, Stock G (1987) Role played by amygdala complex and common brainstem system in integration of somatomotor and autonomic components of behavior. In: Organization of the autonomic nervous system: central and peripheral mechanisms (Ciriello J, Calaresu FR, Renaud LP, Polosa C, eds), pp $347-$ 361. New York: Liss.

Lehmann J, Nagy JI, Atmadja S, Fibiger HC (1980) The nucleus basalis magnocellularis: the origin of a cholinergic projection to the neocortex of the rat. Neuroscience 5:1161-1174.

Levey AI, Hallanger AE, Wainer BH (1987) Cholinergic nucleus basalis neurons may influence the cortex via the thalamus. Neurosci Lett $74: 7-13$.

Longo VG (1966) Effects of scopolamine and atropine on electroencephalographic and behavioral reactions due to hypothalamic stimulation. J Pharmacol 116:198-208.

Mesulam M-M (1982) Tracing neural connections with horseradish peroxidase. Chichester: Wiley.

Mesulam M-M, Van Hoesen GW (1976) Acetylcholinesterase-rich projections from the basal forebrain of the rhesus monkey to neocortex. Brain Res 109:152-157.

Mesulam M-M, Mufson EJ, Levey AI, Wainer BH (1983a) Cholinergic innervation of the cortex by the basal forebrain: cytochemistry and cortical connections of the septal area, diagonal band nuclei, nucleus 
basalis (substantia innominata), and hypothalamus in the rhesus monkey. J Comp Neurol 214:170-197.

Mesulam M-M, Mufson EJ, Wainer BH, Levey AI (1983b) Central cholinergic pathways in the rat: an overview based on an alternative nomenclature (Ch1-Ch6). Neuroscience 10:1185-1201.

Metherate R, Ashe JH (1991) Basal forebrain stimulation modifies auditory cortex responsiveness by an action at muscarinic receptors. Brain Res 559:163-167.

Metherate R, Tremblay N, Dykes W (1987) Acetylcholine permits long-term enhancement of neuronal responsiveness in cat primary somatosensory cortex. Neuroscience 22:75-81.

Metherate R, Tremblay N, Dykcs RW (1988) The effects of acetylcholine on response properties of cat somatosensory cortical neurons. J Neurophysiol 59:1231-1252.

Metherate R, Cox CL, Ashe JH (1992) Cellular bases of neocortical activation: modulation of neural oscillations by the nucleus basalis and endogenous acetylcholine. J Neurosci 12:4701-4711.

Morrell F (1961) Electrophysiological contributions to the neural basis of learning. Physiol Rev 41:443-494.

Motokawa K (1949) Electroencephalograms of man [sicb in the generalization and differentiation of conditioned reflexes. Tohoku J Exp Med 50:225-234.

National Institutes of Health (1985) Guide for the care and use of laboratory animals. Washington, D.C.: Publ No 85-23.

Pascoe JP, Kapp BS (1985) Electrophysiological characteristics of amygdaloid central nucleus neurons during Pavlovian fear conditioning in the rabbit. Behav Brain Res 16:117-133.

Pascoe JP, Supple WF, Kapp BS (1991) Learning and memory: Vertebrate model systems. In: Learning and memory: a biological view (Martinez J, ed), pp 359-407. New York: Academic.

Peck BK, Vanderwolf CH (1991) Effects of raphe stimulation on hippocampal and neocortical activity and behaviour. Brain Res 568 : 244-252.

Rasmussen K, Strecker RE, Jacobs BL (1986) Single unit response of noradrenergic, serotonergic and dopaminergic neurons in freely moving cats to simple sensory stimuli. Brain Res 369:336-340.

Reiner PB, Semba K. Fibiger HC, McGeer FG (1987) Physiological evidence for subpopulations of cortically projecting basal forebrain neurons in the anesthetized rat. Neuroscience 20:629-636.

Rhcinberger MB, Jasper HH (1937) Electrical activity of the cerebral cortex in the unanesthetized cat. Am J Physiol 119:186-196.

Richardson RT, DeLong MR (1987) Tonically active nucleus basalis neurons in the awake monkey project to cerebral corlex. Soc Neurosci Abstr 13:1027.

Richardson RT, DeLong MR (1990) Context-dependent responses of primate nucleus basalis neurons in a go/no-go task. J Neurosci 10 : $2528-2540$.

Richardson RT, Mitchell SJ, Baker FH, DeLong MR (1988) Responses of nucleus basalis of Meynert neurons in behaving monkeys. In: Cellular mechanisms of conditioning and behavioral plasticity (Woody CD, Alkon DL, McGaugh JI, eds), pp 161-173. New York: Plenum.

Riekkinen PJ, Riekkinen P Jr, Paljarvi L, Soininen H, Halonen T, Reinikainen K, Partanen J (1990) Relationship between cholincrgic pathology and EEG slowing. In: Key topics in brain research.
Alzheimer's disease: epidemiology, neuropathology, neurochemistry, clinics (Riederen P, Beckman H, eds), pp 437-445. Berlin: Springer.

Riekkinen P Jr, Sirvio J, Miettinen R, Riekkinen P (1990) Effects of quisqualic NB lesioning on passive avoidance and neocortical $E E G$. Brain Res Bull 24:839-842.

Rigdon GC, Pirch JH (1986) Nucleus basalis involvement in conditioned neuronal responses in the rat frontal cortex. J Neurosci 6:25352542.

Russchen FT, Amaral DG, Price JT, (1985) The afferent connections of the substantia innominata in the monkey, Macaca fascicularis. $\mathbf{J}$ Comp Neurol 242:1-27.

Rye DB, Wainer BH, Mesulam M-M, Mufson EJ, Saper CB (1984) Cortical projections arising from the basal forebrain: a study of cholinergic and non-cholinergic components employing combined retrograde tracing and immunohistochemical localization of choline acetyltransferase. Neuroscience 13:627-643.

Saper CB (1984) Organization of cerebral cortical afferent systems in the rat. I. Magnocellular basal nucleus. J Comp Neurol 222:313-342.

Sato H, Hata Y, Hagihara K, Tsumoto T (1987) Effects of cholinergic depletion on neuron activities in the cat visual cortex. J Neurophysiol 58:781-793

Sillito AM, Kemp JA (1983) Cholinergic modulation of the functional organization of the cat visual cortex. Brain Res 289:143-155.

Steriade M, Parent A, Pare D, Smith Y (1987) Cholinergic and noncholinergic neurons of cat basal forebrain project to reticular and mediodorsal thalamic nuclei. Brain Res 408:372-376.

Stewart DJ, MacFabe DF, Vanderwolf CH (1984) Cholinergic activation of the electroencephalogram: role of the substantia innominata and effects of atropine and quinuclidinyl benzilate. Brain Res 322: 219-232.

Szerb JC (1967) Cortical acetylcholine release and electroencephalographic arousal. J thysiol (Lond) 192:329-345.

Wagner AR, Brandon SE (1989) Evolution of a structured connectionist model of Pavlovian conditioning (AESOP). In: Contemporary learning theories (Klein SB, Mowrer RR, eds), pp 149-189. Hillsdale, NJ: Erlbaum.

Weinherger NM (1982) Effects of conditioned arousal on the auditory system. In: The neural basis of behavior (Beckman AL, ed), pp 6391. Jamaica, NY: Spectrum.

Wenk H, Bigl V, Meyer U (1980) Cholinergic projections from magnocellular nuclei of the basal forebrain to cortical areas in rats. Brain Res Rev 2:295-316.

Wikler A (1952) Pharmacologic dissociation on behavior and EEG sleep patterns in dogs: morphine, $\mathrm{N}$-allylnormorphine and atropine. Proc Soc Exp Biol Med 79:261-265.

Wilson FAW, Kolls E'l (1990) Neuronal responses related to reinforcement in the primate basal forebrain. Brain Res 509:213-231.

Yehle A, Dauth G, Schneiderman N (1967) Correlates of heart rate classical conditioning in curarized rabbits. J Comp Physiol Psychol 64:98-104.

Zaborszky L, Cullinan WE, Braun A (1991) Afferents to basal forebrain cholinergic projection neurons: an update. In: The basal forebrain (Napier TC, ed), pp 43-99. New York: Plenum. 